\title{
Peningkatan Kualitas Batubara Peringkat Rendah dengan Teknik Flash Drying
}

\author{
Ahsonul Anam \\ Balai Teknologi Bahan Bakar dan Rekayasa Desain - BPPT \\ E-mail: ahsonul.anam@bppt.go.id
}

Masuk : 20 Januari 2020

Direvisi : 10 Februari 2020

Disetujui : 28 Februari 2020

\begin{abstract}
Abstrak: Batubara peringkat rendah biasanya ditandai dengan kandungan air yang tinggi dan nilai kalor yang rendah.Agar kandungan airnya turun dan nilai kalornya naik, maka perlu dilakukan pengolahan terlebih dahulu sebelum digunakan. Ada banyak teknologi coal upgrading, dengan menggabungkan penggunaan uap air dengan tekanan, tentunya dengan keunggulan dan kekurangan masing-masing. Teknik flash drying memberikan alternatif teknologi peningkatan kualitas batubara dengan memanfaatkan udara yang tidak terlalu panas dan tekanan yang rendah sehingga biaya operasonalnya menjadi lebih rendah. Percobaan yang dilakukan menggunakan teknik flash drying mampu menurunkan kandungan air batubara secara signifikan, namun kandungan air dalam produk berubah sesuai dengan kondisi lingkungan.
\end{abstract}

Kata kunci: Batubara, Flash Drying, Coal Upgrading

Abstract: Low rank coal is usually characterized by high water content and low heating value. In order to decrease the water content and to increase the calorific value, coal need to be treatment before the use. There are many coal upgrading technologies, utilize steam combine with pressure, with the advantages and disadvantages of each. Flash drying technique provide an alternative technology to improve coal quality by utilizing low temperature hot air and low pressure that reduce the operational costs. Experiments carried out using the flash drying technique can significantly reduce the coal water content, but the water content in the product changes according to environmental conditions.

Keywords: Coal, Flash Drying, Coal Upgrading

\section{PENDAHULUAN}

Sumberdaya batubara Indonesia sekitar 126 milyar ton, tersebar di Sumatera sejumlah $40 \%$ (terbesar di Sumatera Selatan), 58 \% di Kalimantan dan sisanya di Papua, Sulawesi dan Jawa. Potensi batubara Indonesia sebagian besar termasuk kategori batubara muda atau batubara peringkat rendah, dengan perkiraan persentase sebagai berikut : lignit $58,7 \%$, sub bituminus $26,7 \%$, bituminus $14,3 \%$ dan antrasit $0,3 \%$. Sumatera Selatan memiliki sumberdaya batubara sekitar 52,24 milyar ton ( $\pm 40 \%$ cadangan batubara nasional) yang terdiri dari cadangan terbukti 2,14 milyar ton dan cadangan terkira 10,1 milyar ton [1].

Daerah yang memiliki cadangan batubara terbesar adalah Kabupaten Muara Enim, Kabupaten Musi Banyuasin dan Kabupaten Lahat untuk Sumatera Selatan, sedangkan untuk wilayah Kalimantan di daerah Kalimantan Timur dan Kalimantan Selatan.

Berdasarkan data tahun 2018 [1], sumberdaya dan cadangan batubara per propinsi terlihat pada Tabel 1 berikut: 
12 | Ahsonul Anam, Peningkatan Kualitas Batubara Peringkat Rendah....

Tabel 1. Sumberdaya dan Cadangan Batubara Indonesia per propinsi

\begin{tabular}{|c|c|c|c|c|c|c|c|c|c|c|}
\hline \multirow{2}{*}{ No. } & \multirow{2}{*}{ Pulau } & \multirow{2}{*}{ Provinsi } & \multicolumn{5}{|c|}{ Sumberdaya (Juta Ton) } & \multicolumn{3}{|c|}{ Cadangan (Juta Ton) } \\
\hline & & & Hipotetik & Tereka & Tertunjuk & Terukur & Total & Terkira & Terbukti & Total \\
\hline 1 & \multirow{3}{*}{ JAWA } & Banten & 5,470 & 32,920 & 12,600 & 6,498 & 57,568 & 4,609 & 2,608 & 7,217 \\
\hline 2 & & Jawa Tengah & - & 0,820 & - & - & 0,820 & $=$ & $=$ & - \\
\hline 3 & & Jawa Timur & - & 0,080 & - & - & 0,080 & - & - & - \\
\hline 4 & \multirow{8}{*}{ SUMATERA } & Acch & $\cdot$ & 138.510 & 314.224 & $B 21,235$ & 1273,968 & 102902 & 468,069 & 570.971 \\
\hline 5 & & Sumatera Utara & . & 7.000 & 1,838 & 5,780 & 14,618 & $=$ & . & - \\
\hline 6 & & Rias & 3.860 & 521.216 & 810.606 & 525.707 & 1.861 .390 & 198.476 & 382.787 & 581.263 \\
\hline 7 & & Summetera Barat. & 1,194 & 156,705 & $\pi, 060$ & 241,615 & 476.574 & 19,271 & 98,866 & 118,137 \\
\hline 8 & & Jambi & 140,307 & 2959,865 & 2093.832 & $2.262,161$ & $7.456,156$ & 1.227 .161 & $1.130,190$ & 2357,361 \\
\hline 9 & & Bengkula & - & 183.342 & 193,077 & 181,007 & 557.426 & 65.500 & 112,028 & 177.600 \\
\hline 10 & & Sumatera Selatan & $3.099,447$ & 13.062 .940 & $13.686,406$ & $12.100,875$ & $41.949,658$ & 5912,000 & 4. 165,615 & $10,077.616$ \\
\hline 11 & & Lampung & - & 122,949 & 8.210 & 3,534 & 134,693 & 11,744 & - & 11,744 \\
\hline 12 & \multirow{5}{*}{ KALLIMANTAI } & Kalimantan Barat & 2.257 & 375,690 & 6.850 & 3,700 & 368.497 & $=$ & $\%$ & 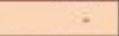 \\
\hline 13 & & Ksimartan Tengah & 22,540 & $5.209,692$ & $2.576,000$ & 2292,513 & 10.100 .745 & $1.315,006$ & $1.383,964$ & $2.698,970$ \\
\hline 14 & & $\sqrt{\text { Kalmantan Selatan }}$ & - & 6817,365 & 4949,010 & 7607,006 & $19,373,381$ & 2.216 .290 & 2894,315 & $5.110,605$ \\
\hline 15 & & Kalimartan Timur & 887,906 & 13.144 .992 & 26589,914 & $23.693,349$ & $64,316,241$ & $5,735,166$ & $11.101,932$ & 16837.096 \\
\hline 16 & & Kaimantan Utara & 25,790 & 1.267 .530 & 918,092 & $1.017,932$ & 3.229 .343 & 750,822 & 589,421 & 1.340 .243 \\
\hline 17 & \multirow{4}{*}{ SULAWESI } & Sulawesi Barat & 11,463 & 15,999 & 0.780 & 0.165 & 28,407 & 1,8 & - & 1.800 \\
\hline 18 & & Sulawesi Selatan & 10,662 & 13,900 & 7,630 & 0.440 & 32,632 & $=$ & 0,332 & 0.332 \\
\hline 19 & & Sulawesi Tenggara & 0,636 & - & - & - & 0,636 & - & - & - \\
\hline 20 & & Sulawesi Tengah & 0.524 & 1,960 & - & - & 2.504 & - & - & - \\
\hline 21 & MALUKU & Maluku Utara & 8,217 & $=$ & $=$ & - & 8.217 & $=$ & $=$ & $=$ \\
\hline 22 & \multirow{2}{*}{ PAPUA } & Papua Barat & 93,663 & 32,820 & - & - & 126,483 & - & - & - \\
\hline 23 & & Papua & 7,197 & 2,160 & - & - & 9.357 & - & - & - \\
\hline \multicolumn{3}{|c|}{ TOTAL INDONESIA } & $4.321,21$ & $44.068,47$ & $52.246,21$ & $50.763,52$ & $151.399,40$ & $17,560,83$ & $22.330,13$ & $39.890,95$ \\
\hline
\end{tabular}

Meskipun dari segi potensi, Indonesia memiliki cadangan batubara yang sangat besar, tetapi sebagian besar yakni lebih dari 9,5 milyar ton merupakan batubara peringkat rendah dengan nilai kalor yang rendah (Gambar 1). Batubara peringkat rendah ini biasanya ditandai dengan kandungan air yang tinggi dan nilaikalor yang rendah. Oleh karena sifatnya tersebut menyebabkan batubara peringkat rendah kurang atau bahkan tidak memiliki nilai ekonomis.

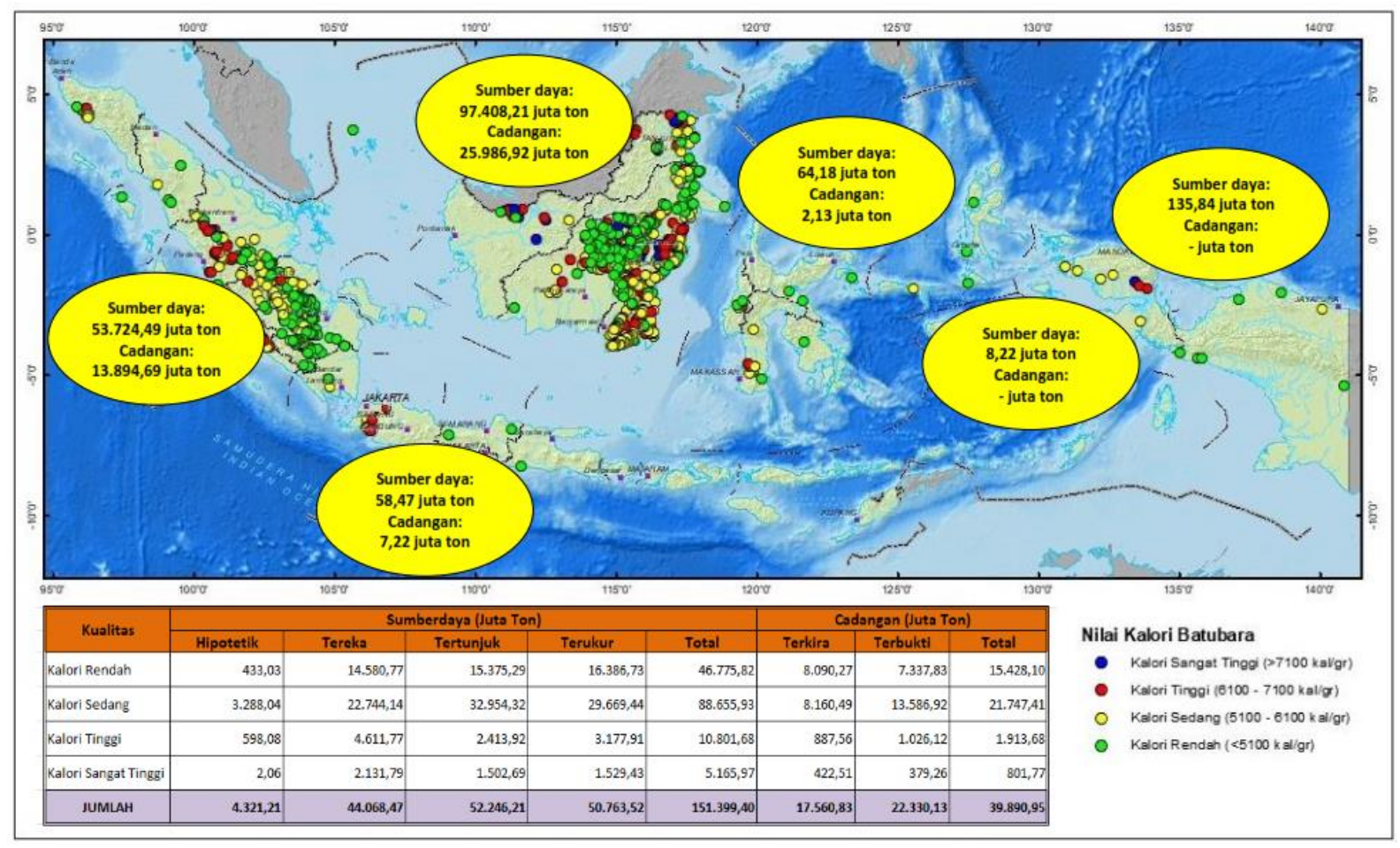

Gambar 1. Kualitas, Sumberdaya dan Cadangan Batubara Indonesia, 2018 [1]. 
Kualitas batubara merupakan faktor kunci pada boiler pada PLTU atau industri. Sistem pada ruang bakar memiliki keterbatasan dalam penggunaan batubara, karena dirancang menggunakan batubara dengan kisaran karakteristik tertentu. Untuk itu, boiler tersebut idealnya memerlukan jaminan pasokan batubara yang sesuai dengan spesifikasinya minimal selama umur operasinya. Namun, kesulitan dalam penyediaan batubara tersebut kenyataannya sering terjadi karena beberapa kendala teknis maupun finansial. Untuk itu skenario berikut umumnya dipilih oleh pihak PLTU, (1) menggunakan batubara pengganti/alternatif, (2) melakukan sistem coal blending dan atau (3) melakukan upgrading [2].

Alternatif pertama, pemakaian batubara pengganti dengan karakteristik yang tidak sesuai dengan spesifikasi bahan bakar boiler desain bisa menyebabkan terjadinya beberapa permasalahan operasional yang berdampak terhadap permasalahan teknis. Pertama, penurunan efisiensi pembakaran bisa terjadi akibat penggunaan batubara dengan kandungan air tinggi. Artinya, PLTU memerlukan batubara yang lebih banyak untuk setiap pemenuhan kebutuhan energi dalam jumlah yang sama.

Upaya kedua adalah dengan melakukan coal blending yaitu dengan cara mencampur batubara peringkat tinggi dengan batubara peringkat rendah sehingga sesuai atau mendekati spesifikasi kebutuhan desain boilernya.

Upaya ke tiga adalah dengan melakukan upgrading (peningkatan kualitas) batubara, yaitu dengan cara menurunkan kandungan air batubara sehingga kandungan kalor per kg batubara meningkat.

\section{TINJAUAN PUSTAKA}

Teknik pengurangan kandungaan air dalam batubara melibatkan parameter suhu dan tekanan. Berdasarkan suhu dan tekanan yang digunakan dalam proses, Teknik upgrading dibagi menjadi 4 kategori, yaitu proses pengeringan dengan suhu dan tekanan rendah, proses pengeringan dengan suhu tinggi dan tekanan rendah, proses pengeringan dengan suhu rendah dan tekanan tinggi dan proses pengeringan dengan suhu dan tekanan tinggi, seperti terlihat pada Gambar 2.

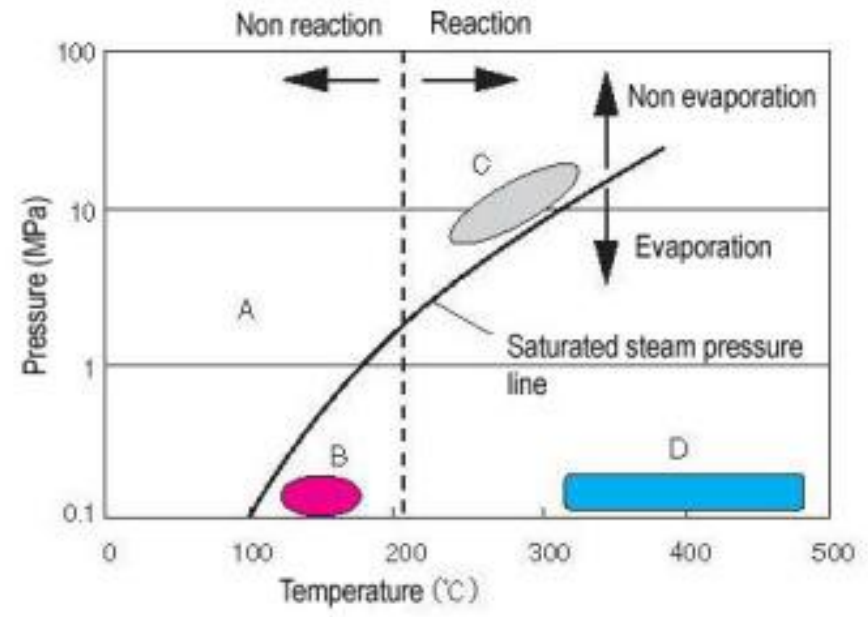

\begin{tabular}{|c|c|c|l|}
\hline & Evaporasi & Reaksi & \multicolumn{1}{|c|}{ Aplikasi proses } \\
\hline $\begin{array}{c}\text { A } \\
\text { (Press, dewatering) }\end{array}$ & $\Delta$ & $\mathrm{X}$ & MTE, ColdDry \\
\hline $\begin{array}{c}\text { B } \\
\text { (Evapcrasi) }\end{array}$ & $\mathrm{O}$ & $\mathrm{X}$ & $\begin{array}{l}\text { Tube dryer, fuidized bed (WTA, Dry Fen, Tokyo UniwMHI, etc) } \\
\text { IDGCC, BCB, UBC, SYNCOL }\end{array}$ \\
\hline $\begin{array}{c}\text { C } \\
\text { (Non evaporasi) }\end{array}$ & $\mathrm{X}$ & $\mathrm{O}$ & $\begin{array}{l}\text { Fleisner, HWT, Exergen, K-Fud, } \\
\text { Hydrothermal extraction (solven extraction) }\end{array}$ \\
\hline $\begin{array}{c}\text { D } \\
\text { (Pirolisis) }\end{array}$ & $\bigcirc$ & $\bigcirc$ & ENCOL, LaTrobe Lignite Development \\
\hline
\end{tabular}

Gambar 2. Proses Pengeringan Batubara dengan Parameter Suhu dan Tekanan [3] 


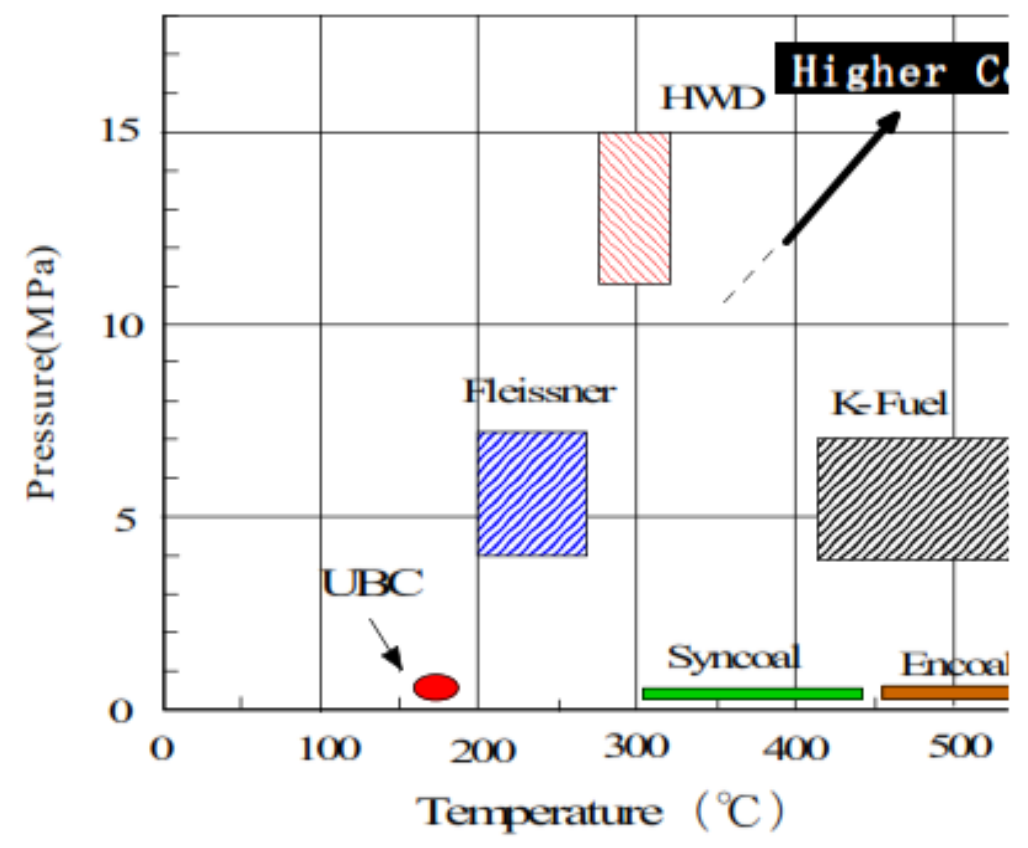

Gambar 3. Aplikasi Proses Pengeringan Batubara dengan Parameter Suhu dan Tekanan [4].

Dari Gambar 3 terlihat beberapa aplikasi proses pengeringan yang melibatkan suhu di atas $200^{\circ} \mathrm{C}$ dengan tekanan rendah (Syncoal, Encoal) serta melibatkan tekanan (Fleisner, K-Fuel, HWD).

Sedangkan aplikasi pengeringan batubara yang beroperasi dengan suhu di bawah $200^{\circ} \mathrm{C}$ dan tekanan rendah di antaranya adalah UBC (Upgrading Brown Coal). Kelebihan proses UBC bila dibandingakan dengan proses upgrading lainnya adalah proses UBC memiliki kondisi operasi yang jau lebih mild yaitu dioperasikan pada suhu $140^{\circ} \mathrm{C}$ dan tekanan $350 \mathrm{kPa}$ [4].

Sedangakan sistem flash drying adalah salah satu metode pengeringan yang cukup menjanjikan untuk dibuat dalam skala komersial. Pada metode ini, pengeringan dilakukan pada suhu di bawah $200^{\circ} \mathrm{C}$ dan tekanan atmosferik, waktu pengeringan dilakukan cepat, sehingga biaya pengeringan menjadi lebih rendah.

\section{METODOLOGI}

Masalah pada penelitian ini adalah usaha untuk menurunkan kandungan air batubara sehingga nilai kalor batubara tersebut meningkat tanpa sehingga bisa langsung dimanfaatkan sebagai bahan bakar PLTU di lokasi yang sama atau dibriketkan sehingga kandungan air batubara hasil upgrading relatif stabil yang pada akhirnya batubara tersebut bisa dimanfaatkan untuk kebutuhan industri lainnya.

Kegiatan ini difokuskan pada pengujian kondisi operasi pada alat coal flash drying Gambar 4 dan setelah dilakukan pembriketan (Gambar 5) dilakukan pengamatan kestabilan kandungan air selama beberapa hari.

Batubara sampel dilakukan analisa proksimat maupun ultimat serta kandungan kalornya. Batubara sampel kemudian digerus menggunakan crusher dan mill sehingga didapatkan batubara dengan ukuran sesuai dengan kebutuhan, kemudian dilakukan uji distribusi partikel. Sebelum dilakukan uji di alat flash dryer, dilakukan penyampelan batubara tersebut untuk dilakukan uji kandungan air.

Sebelum pelaksanaan uji di flash dryer, ditetapkan terlebih dahulu parameter-parameter pengujian. Batubara halus diumpankan ke dalam alat uji flash dryer dengan kecepatan pemasukan (feeding) tertentu, dan dilakukan pencatatan beberapa parameter pengujian selama proses pengujian berlangsung. Produk pengeringan ditampung, dilakukan penyampelan untuk dilakukan uji kandungan airnya.

Batubara produk hasil pengeringan kemudian dilakukan pembriketan dengan kondisi dan parameter pembriketan tertentu, tanpa penambahan aditif lainnya (binderless), menggunakan alat double roll press.

Produk briket batubara kemudian dilakukan penimbangan, mulai pada hari ke $0,1,2$ dan seterusnya untuk dilakukan pemantauan bila terjadi pengurangan atau penambahan berat briket setelah dilakukan pemaparan briket sampel di ruang terbuka namun beratap selama hari pemantauan. 


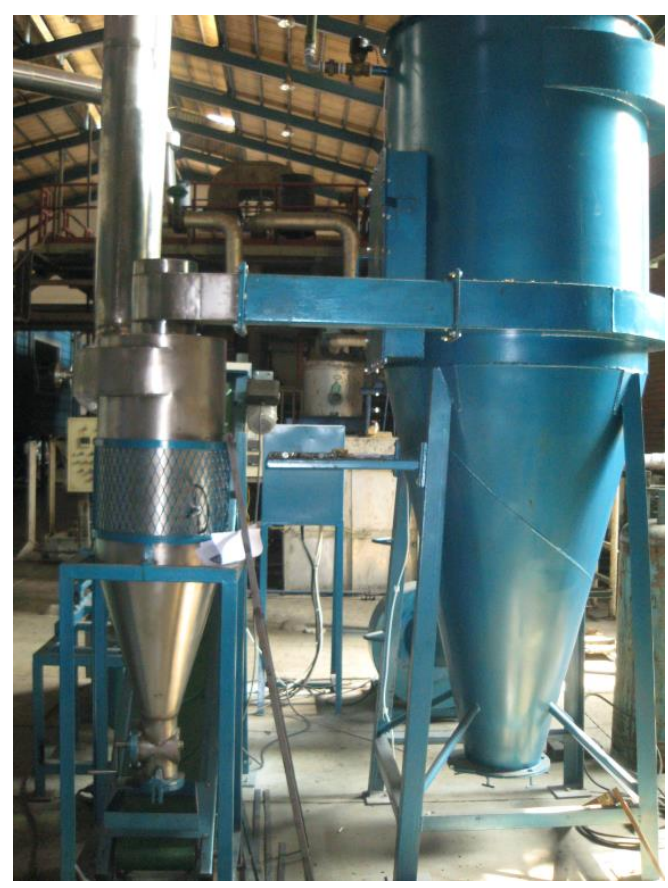

Gambar 4. Coal Fash Drying

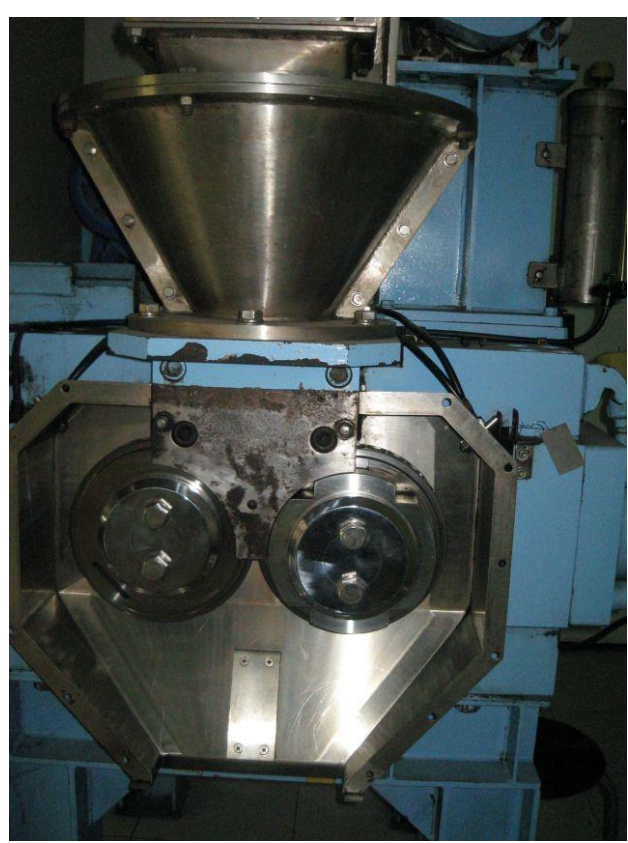

Gambar 5. Pencetak Briket Batubara Double Roll

Variable Pengujian

a. Variable Tetap.

Jenis Batubara : Batubara S

Ukuran Partikel : Lolos 8 mesh

Suhu Udara Pemanas Input $: 114^{\circ} \mathrm{C}$

Pembriketan :

Tipe roll : Pillow

Kecepatan roll $\quad: 4 \mathrm{rpm}$

b. Variabel Tidak Tetap

Kecepatan feed di Pengering : $40 \mathrm{~kg} / \mathrm{jam}$

Tekanan Pembriketan : $5 \mathrm{~kg} / \mathrm{cm}^{2}$ s.d $160 \mathrm{~kg} / \mathrm{cm}^{2}$

\section{HASIL DAN PEMBAHASAN}

Hasil analisa batubara S sebagai berikut :

Tabel 2. Hasil Analisa Proksimat

\begin{tabular}{ccc}
\hline$\%$ Total Air (ar) & 49,95 & ASTM D-3302 \\
\hline Analisa Proksimat & & ASTM D-5142 \\
\hline$\%$ Air (adb) & 10,11 & \\
\hline$\%$ Ash (adb) & 16,77 & \\
\hline$\%$ Volatile Matter (adb) & 39,49 & By Difference \\
\hline
\end{tabular}


16 | Ahsonul Anam, Peningkatan Kualitas Batubara Peringkat Rendah....

Tabel 3. Distribusi Ukuran Partikel

\begin{tabular}{cccccc}
\hline $\begin{array}{c}\text { No Ayakan } \\
(\mathrm{mesh})\end{array}$ & $\begin{array}{c}\text { Berat Ayakan } \\
(\mathrm{gr})\end{array}$ & $\begin{array}{c}\text { Ayakan+Sampel } \\
(\mathrm{gr})\end{array}$ & Berat Tertahan $(\mathrm{gr})$ & Berat Tertahan $(\%)$ & $\begin{array}{c}\sum \text { Berat } \\
(\%)\end{array}$ \\
\hline 8 & 403,65 & 408,84 & 5,19 & 10,38 & 10,59 \\
16 & 364,14 & 384,79 & 20,65 & 41,30 & 52,70 \\
30 & 425,82 & 434,61 & 8,79 & 17,58 & 70,63 \\
50 & 291,87 & 295,88 & 4,01 & 8,02 & 78,81 \\
100 & 286,74 & 291,02 & 4,28 & 8,56 & 87,54 \\
200 & 276,07 & 278,52 & 2,45 & 4,90 & 92,54 \\
Alas & 385,97 & 398,63 & 3,66 & 7,32 & 100 \\
\hline
\end{tabular}

Adapun analisa kandungan air sampel batubara sebelum dilakukan pengujian di flash dryer, ditunjukkan pada tabel 4 berikut :

Tabel 4. Analisa air sampel batubara sebelum pengujian

\begin{tabular}{ccccccc}
\hline No. & $\begin{array}{c}\text { Massa Crusible } \\
(\mathrm{gr})\end{array}$ & $\begin{array}{c}\text { Massa Total } \\
(\mathrm{gr})\end{array}$ & $\begin{array}{c}\text { Massa Sampel } \\
(\mathrm{gr})\end{array}$ & $\begin{array}{c}\text { Massa } \\
\text { Akhir }(\mathrm{gr})\end{array}$ & $\begin{array}{c}\text { Pengurangan } \\
(\mathrm{gr})\end{array}$ & Total Air $(\%)$ \\
\hline 1 & 8,4273 & 9,4273 & 1 & 8,9412 & 0,4861 & 48,61 \\
2 & 8,8599 & 9,8599 & 1 & 9,3693 & 0,4906 & 49,06 \\
3 & 8,1635 & 9,1635 & 1 & 8,6721 & 0,4914 & 49,14 \\
\hline & & Rata-rata & & 48,94 \\
\hline
\end{tabular}

Kondisi operasi di alat flash dryer adalah sebagai berikut :

Kondisi tanpa umpan batubara sampel :

\begin{tabular}{ccccc}
\hline Heater & Suhu I & Suhu II & Suhu III & Suhu IV \\
\hline 114 & 108,4 & 105,3 & 102,3 & 99,3 \\
\hline
\end{tabular}

Ket. Suhu I, II, III dan IV adalah suhu di sepanjang alat pengeringan.

Kondisi beban batubara sampel dengan laju umpan $40 \mathrm{~kg} / \mathrm{jam}$ :

\begin{tabular}{ccccc}
\hline Heater & Suhu I & Suhu II & Suhu III & Suhu IV \\
\hline 114 & 106,3 & 93,1 & 87 & 85 \\
\hline
\end{tabular}

Tabel 5. Analisa air sampel batubara setelah pengujian

\begin{tabular}{ccccccc}
\hline No. & $\begin{array}{c}\text { Massa Crusible } \\
(\mathrm{gr})\end{array}$ & $\begin{array}{c}\text { Massa Total } \\
(\mathrm{gr})\end{array}$ & $\begin{array}{c}\text { Massa Sampel } \\
(\mathrm{gr})\end{array}$ & $\begin{array}{c}\text { Massa Akhir } \\
(\mathrm{gr})\end{array}$ & $\begin{array}{c}\text { Pengurangan } \\
(\mathrm{gr})\end{array}$ & Total Air $(\%)$ \\
\hline 1 & 8,4299 & 9,4299 & 1 & 9,1009 & 0,3290 & 32,90 \\
2 & 8,1656 & 9,1565 & 1 & 8,8530 & 0,3126 & 31,26 \\
3 & 8,8620 & 9,8620 & 1 & 9,5301 & 0,3319 & 33,19 \\
\hline \multicolumn{7}{c}{ Rata-rata } \\
\hline
\end{tabular}


Tabel 6. Massa sampel briket pada masing-masing kondisi tekanan pembriketan $\left(\mathrm{kgf} / \mathrm{cm}^{2}\right)$

\begin{tabular}{|c|c|c|c|c|c|c|c|c|c|c|}
\hline \multirow{2}{*}{$\begin{array}{c}\text { Hari } \\
\text { ke - }\end{array}$} & \multicolumn{10}{|c|}{ Massa sampel (gram) } \\
\hline & 5 & 10 & 20 & 60 & 80 & 120 & 130 & 140 & 150 & 160 \\
\hline 1 & 75,1918 & 81,6240 & 83,4842 & 83,0886 & 81,2112 & 84,3473 & 83,8920 & 83,7797 & 83,3212 & 84,5334 \\
\hline 2 & 73,9597 & 79,8589 & 82,1172 & 81,1233 & 81,1792 & 82,7147 & 82,0882 & 82,2051 & 82,0715 & 82,8926 \\
\hline 3 & 72,7172 & 78,1903 & 80,2515 & 79,2925 & 79,4988 & 80,855 & 80,2873 & 80,4804 & 80,5579 & 81,2078 \\
\hline 4 & 71,7728 & 76,9541 & 78,8226 & 77,8631 & 78,0264 & 79,4059 & 78,9086 & 79,2252 & 79,4402 & 79,7670 \\
\hline
\end{tabular}

Kandungan air batubara uji sebelum dilakukan pengeringan melaui Teknik flash drying adalah 48, $94 \%$ (Tabel 4), dan setelah melalui proses pengeringan terjadi penurunan kandungan air menjadi 32,45 \% (Tabel 5). Hasil pengeringan menggunakan teknik flash drying sebaiknya mendekati ke kandungan air inherent yaitu 10,11 $\%$ (Tabel 2), walaupun telah terjadi dipenurunan kandungan air secara signifikan.

Dari Tabel 6 dapat dilihat bahwa, kandungan air batubara uji, walau sudah dilakukan pembriketan dengan variasi tekanan, dari hari ke 1 sampai dengan hari ke 4 masih mengalami penurunan massa. Hal ini mengindikasikan beberapahal di antaranya :Pertama, proses pengeringan kurang maksimal karena hasil akhir proses kandungan air batubara sebesar 32,45 \% masih jauh dari kandungan air inherent yaitu 10,11\%. Yang kedua, dengan pembriketan kurang bisa mengendalikan kandungan air batubara. Hal ini disebabkan suhu udara pemanas yang relatif rendah, hanya bisa menguapkan air dalam batubara, tanpa terjadi proses pengeluaran tar. Pengeluaran tar diharapkan bisa menjadi pelapis di permukaan briket sehingga kandungan air dalam produk akhir menjadi lebih stabil [5].

\section{KESIMPULAN}

Penggunaan alat flash drying yang memanfaatkan udara panas bersuhu relatif rendah, mampu menurunkan kandungan air dalam batubara secara signifikan, namun kandungan air dalam produk yang dihasilkan masih masih tinggi.

\section{DAFTAR PUSTAKA}

[1] Executive Summary Pemutakhiran Data dan Neraca Sumberdaya Energi Tahun 2018, Pusat Sumber Daya Mineral, Batubara dan Panas Bumi, Badan Geologi, http://psdg.geologi.esdm.go.id/images/stories/neraca/2018/ExSumNeracaMinerba2018.pdf

[2] Christian Vogt, Thomas Wild, Christian Bergins, Karl Strau, Janine Hulston, Alan L Chaffe, Mechanical/thermal Dewatering of Lignite, Part 4 : Physico-chemical Properties and Pore Structure During an Acid Treatment Within the MTE Process, 2011, Elsevier Journal, www.elsevier.com/locate/fuel

[3] Imam Budi Raharjo, Teknologi Pengeringan Lignit, 2011, https://imambudiraharjo.wordpress.com/2011/06/17/teknologi-pengeringan-lignit/

[4] Hartiniati, Uji Peningkatan Mutu Batubara Peringkat Rendah Sumatera Selatan, Jurna Energi dan Lingkungan Vol. 7, No. 1, Juni 2011.

[5] WCI or World Coal Institute (2009), Coal statistic on Indonesia, www.worldcoal.org, February 2019 